\title{
Histone deacetylase inhibitor SAHA mediates mast cell death and epigenetic silencing of constitutively active D816V KIT in systemic mastocytosis
}

\author{
Katarina Lyberg 1,3, Hani Abdulkadir Ali2,3, Jennine Grootens ${ }^{1,3}$, Matilda Kjellander ${ }^{2}$, \\ Malin Tirfing ${ }^{1}$, Michel Arock ${ }^{4}$, Hans Hägglund ${ }^{5}$, Gunnar Nilsson ${ }^{1,3, *}$, Johanna \\ Ungerstedt $\mathbf{t}^{2,3, *}$ \\ ${ }^{1}$ Immunology and Allergy Unit, Department of Medicine Solna, Karolinska Institutet and clinical immunology and transfusion \\ medicine, Karolinska University Hospital, Stockholm, Sweden \\ ${ }^{2}$ Department of Medicine Huddinge, Karolinska Institutet and Hematology Center, Karolinska University Hospital, Stockholm, \\ Sweden \\ ${ }^{3}$ Mastocytosis Center Karolinska, Karolinska University Hospital and Karolinska Institutet, Stockholm, Sweden \\ ${ }^{4}$ Molecular and Cellular Oncology, LBPA CNRS UMR 8113, Ecole Normale Supérieure de Cachan, Cachan, France and \\ Laboratoire Central d'Hématologie, Groupe Hospitalier Pitié-Salpêtrière, Paris, France \\ ${ }^{5}$ Department of Medical Sciences, Uppsala University and Section of Hematology, Uppsala University Hospital, Uppsala, \\ Sweden \\ *These authors have contributed equally to this work \\ Correspondence to: Gunnar Nilsson, email: gunnar.p.nilsson@ki.se
}

keywords: systemic mastocytosis, epigenetics, KIT, chromatin, mast cells

Received: January 27, $2016 \quad$ Accepted: December 05, 2016

Published: December 25, 2016

\section{ABSTRACT}

Systemic mastocytosis (SM) is a clonal bone marrow disorder, where therapeutical options are limited. Over $90 \%$ of the patients carry the $\mathrm{D} 816 \mathrm{~V}$ point mutation in the KIT receptor that renders this receptor constitutively active. We assessed the sensitivity of primary mast cells (MC) and mast cell lines HMC1.2 (D816V mutated), ROSA (KIT WT) and ROSA (KIT D816V) cells to histone deacetylase inhibitor (HDACi) treatment. We found that of four HDACi, suberoyl anilide hydroxamic acid (SAHA) was the most effective in killing mutated MC. SAHA downregulated KIT, followed by major MC apoptosis. Primary SM patient MC cultured ex vivo were even more sensitive to SAHA than HMC1.2 cells, whereas primary MC from healthy subjects were less affected. There was a correlation between cell death and SM disease severity, where cell death was more pronounced in the case of aggressive SM, with almost $100 \%$ cell death among MC from the mast cell leukemia patient. Additionally, ROSA (KIT D816V) was more affected by HDACi than ROSA (KIT WT) cells. Using ChIP qPCR, we found that the level of active chromatin mark $\mathrm{H} 3 \mathrm{~K} 18 \mathrm{ac} / \mathrm{H} 3$ decreased significantly in the KIT region. This epigenetic silencing was seen only in the KIT region and not in control genes upstream and downstream of KIT, indicating that the downregulation of KIT is exerted by specific epigenetic silencing. In conclusion, KIT D816V mutation sensitized MC to HDACi mediated killing, and SAHA may be of value as specific treatment for SM, although the specific mechanism of action requires further investigation.

\section{INTRODUCTION}

Systemic mastocytosis (SM) is a rare clonal bone marrow disease, previously defined as a subtype of myeloproliferative neoplasms but has recently been redefined as an own disease entity in the 2016 WHO classification of hematological malignancies [1]. SM is characterized by elevated numbers of mast cells (MC) in one or more tissues, almost always including the bone marrow, and enhanced levels of MC mediators, typically tryptase and histamine $[2,3]$. Symptoms originate from the MC burden itself and/or MC released mediators. SM 
may be indolent (ISM), with no impact on life expectancy, or aggressive (ASM) with a survival of 1-2 years. Mast cell leukemia (MCL), which is the most aggressive category of SM, is characterized by $>20 \%$ of malignant circulating MCs and has the worst prognosis of all SM categories, median overall survival being less than 6 months. Management options are limited to symptomatic treatment, and there is no curative therapy $[2,4,5]$, except for allogeneic stem cell transplantation, however the majority of ASM patients are elderly and not eligible for stem cell transplant [6].

The development, growth and survival of $\mathrm{MC}$ are dependent on the binding of stem cell factor (SCF) to the tyrosine kinase receptor KIT [7, 8]. More than $90 \%$ of SM patients carry a point mutation (most commonly D816V) in the kinase domain of the KIT receptor rendering the receptor constitutively active [9]. D816V mutated SM is resistant to treatment with tyrosine kinase inhibitors like Imatinib [10], however two recent studies with the novel broad tyrosine kinase inhibitor Midostaurin shows promising data with an overall response rate of $60 \%$ in patients with aggressive forms of SM $[11,12]$. KIT receptor mutations are considered essential for the development of SM, however little is known about the regulation of $K I T$ expression in normal or neoplastic human MC.

Epigenetic changes include DNA methylation and posttranslational modifications of histones, the regulation of which is frequently perturbed in myeloid malignancies such as the myelodysplastic syndromes and myeloproliferative neoplasms [13]. In recent years, several point mutations in genes encoding epigenetic regulators have been detected in such malignancies, with implications for their pathogenesis, progression and prognosis $[14,15]$. Similar mutation patterns are also present in SM [16, 17] and accumulating evidence indicates that improved understanding of these recurrent mutations allow prediction of development towards aggressive disease phenotypes [18-21].

Histone deacetylase inhibitors (HDACi) are small molecules of various structure background of which many are in clinical trials for solid and hematological tumors, and a few are already approved for some specific tumor subtypes [22]. The HDACi suberoyl anilide hydroxamic acid (SAHA) is a pan-inhibitor of class I and II HDACs, and in addition also affects acetylation of non-histone proteins, of which one of the most extensively studied is HSP90 [23, 24]. Treatment with SAHA alters the expression of $5-15 \%$ of protein coding genes, depending on cell type $[22,25,26]$. SAHA induces apoptosis in malignant cells [27] and is currently in phase I-III clinical trials for treatment of a variety of solid and hematological malignancies, and is approved for treatment of cutaneous $\mathrm{T}$ cell lymphoma, as is Romidepsin in the US. Recently, Panobinostat, another HDACi similar in function to SAHA, was approved as third line treatment in a combination regimen, for myeloma. In human GIST tumors that frequently carry KIT mutations, however not commonly the D816V mutation, SAHA and other HDACi have been shown to decrease KIT mRNA levels and acetylate HSP90, abrogating its activity as a KIT chaperone [24]. Additionally, the HDACi AR-42 has been described to downregulate constitutively active KIT in malignant murine and canine mast cells [28], although the underlying mechanism remains unclear.

The purpose of this study was to characterize the effect of HDACi in human SM cells. We demonstrate that in human SM cell lines carrying the D816V mutation, SAHA downregulates KIT mRNA followed by decreased KIT protein levels, cell surface KIT expression and apoptosis, and that the mechanism is at least partially via epigenetic silencing. In addition, we show that primary mast cells from SM patients are highly sensitive to SAHA-induced cell death, whereas normal bone marrow mast cells are resistant. Thus, HDACi may be a potential clinical treatment option for SM patients.

\section{RESULTS}

\section{HDACi reduces HMC1.2 growth and viability}

SAHA, Romidepsin and Panobinostat, three inhibitors of class I and II HDACs, and Valproic acid, an inhibitor of class I HDACs, were assessed for doseand time-dependent effects on HMC1.2 growth and viability. All HDACi induced a dose- and time-dependent decrease in HMC1.2 growth (Figure 1A-1D), with a concomitant decrease in cell viability (Figure 2A-2D). As SAHA induced an earlier and more profound decrease in both growth and viability, we used SAHA for further investigations in our study.

\section{SAHA reduces KIT expression and induces apoptosis in HMC1.2 cells}

Viability was further analyzed by flow cytometry in Annexin $\mathrm{V}$ and propidium iodide stained cells. We found that the decrease in viability was mainly due to a profound increase in apoptotic cell death at $48 \mathrm{~h}(\mathrm{p}<0.01$, Figure $3 \mathrm{~A})$. Already at $24 \mathrm{~h}$ there was a significant decrease of KIT mRNA ( $p<0.01$, Figure $3 B)$, as well as a significant reduction in the percentage of high surface KIT positive cells ( $<0.01$ at $24 \mathrm{~h}$, Figure $3 \mathrm{C}$ ). Thus, the decrease in growth, KIT mRNA and cell surface KIT clearly preceded the apoptotic cell death. When assessing protein levels, we observed a significant increase in active histone mark $\mathrm{H} 3 \mathrm{~K} 27 \mathrm{ac}$ already at $2 \mathrm{~h}$ and a decrease in phosphorylated active KIT at $6 \mathrm{~h}(\mathrm{p}<0.05$, Figure 3D), indicating an early onset of SAHA mediated effects. Total KIT protein level was significantly decreased at $24 \mathrm{~h}$, co-occurring with the 
A

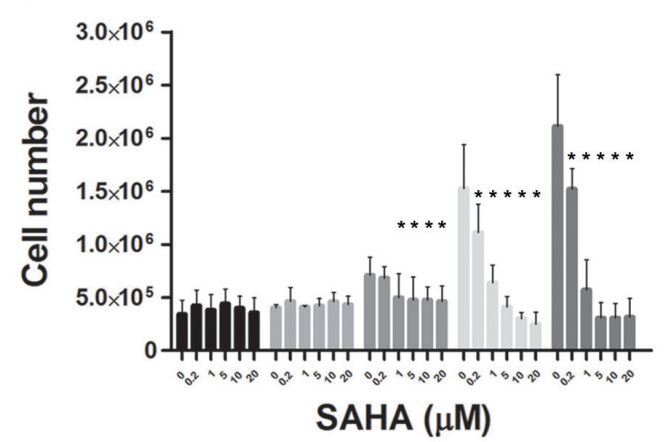

C

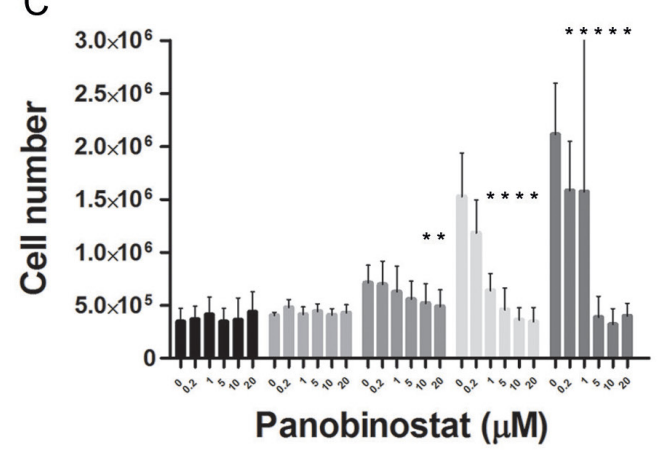

B

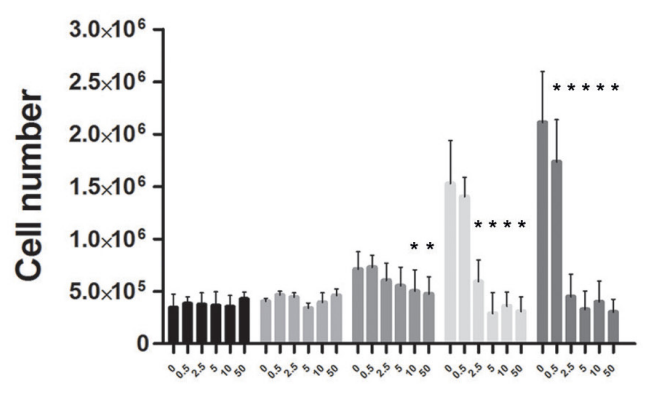

Romidepsin (nM)

D

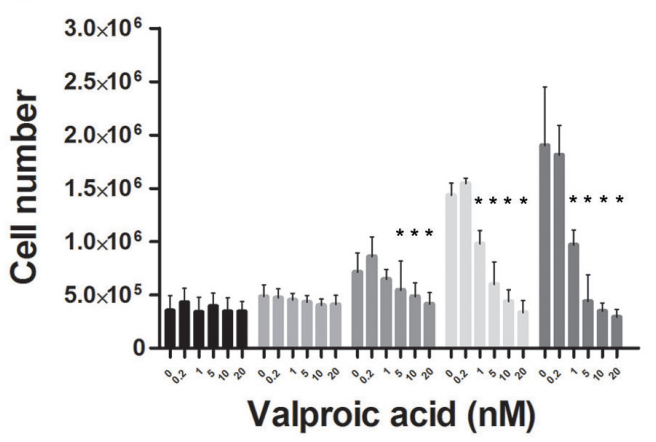

Figure 1: HDACi induces HMC1.2 mast cell line growth inhibition. There was a dose- and time-dependent inhibition of cell growth upon culture of HMC1.2 cell line with: A. SAHA, B. Romidepsin, C. Panobinostat and D. Valproic acid. Triplicates of three biological replicates were analyzed. The earliest and also most profound effects were seen upon treatment with SAHA. * indicates significance on the level of $\mathrm{p}<0.05$.

A

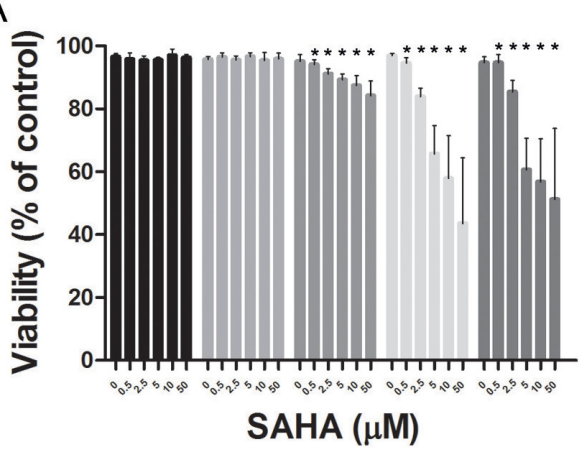

C

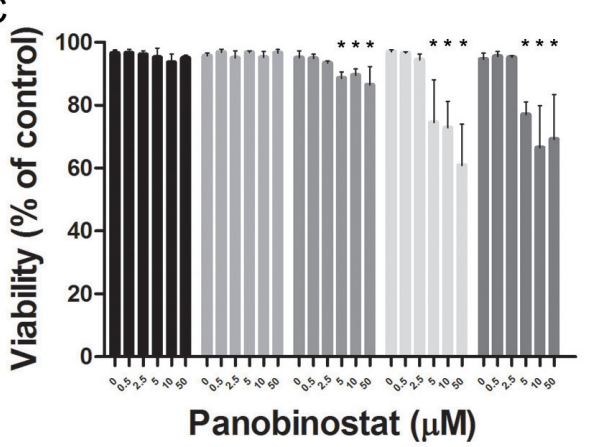

$\mathrm{B}$
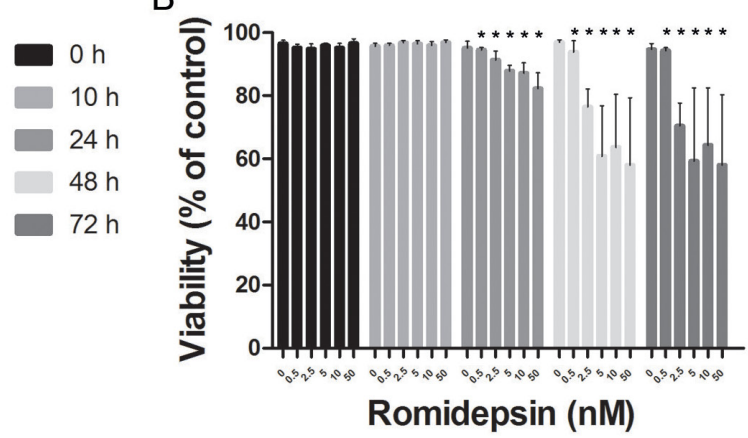

$\mathrm{D}$

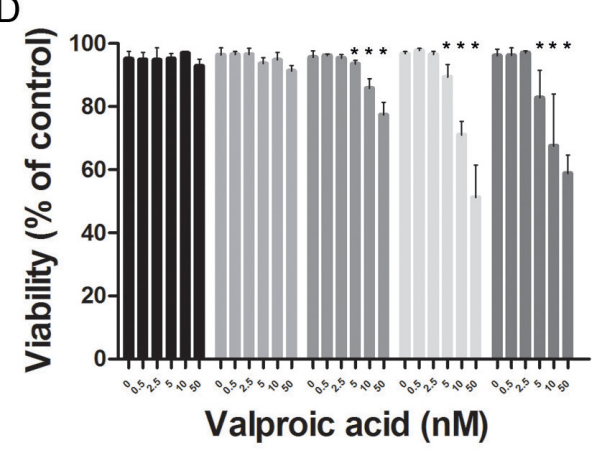

Figure 2: Decrease in HMC1.2 mast cell line viability after treatment with HDACi. There was a dose- and time-dependent decrease in cell viability of HMC1.2 cells by: A. SAHA, B. Romidepsin, C. Panobinostat and D. Valproic acid. Viability was determined by Annexin V and PI staining, and triplicates of three biological replicates were analyzed. Of the four HDACi, SAHA was the most efficient in decreasing cell viability. * indicates significance on the level of $\mathrm{p}<0.05$. 
decrease in percentage KIT positive cells, and KIT mRNA. Cleaved caspase 3 was also significantly increased at $24 \mathrm{~h}$ as a first sign of apoptosis induction ( $p<0.05$, Figure 3D).

\section{Additional targets of SAHA in HMC1.2 cells}

We thereafter set out to investigate transcription factors potentially regulating KIT expression. We chose ten transcription factors known as KIT regulators in mouse models, or proposed as regulators of human KIT, namely E2A, ETS2, GATA1, GATA2, Ldb1, LMO2, MYB, SCL, $\mathrm{Sp} 1$ and Sp3, and assessed the transcript levels of these transcription factors after $24 \mathrm{~h}$ culture of HMC1.2 with $5 \mu \mathrm{M}$ SAHA. We found that SAHA induced a significant decrease in MYB. (Figure 4A). The downregulation of MYB by SAHA was also confirmed at protein level by western blot, where a representative blot is shown in Figure 4B. Thus, SAHA downregulates transcription factor MYB at mRNA and protein level, and MYB may be one contributing factor in the downregulation of KIT exerted by SAHA.

\section{SAHA reduces active phosphorylated KIT and mediates apoptosis in ROSA ${ }^{\text {KIT WT }}$ but even more profound in ROSA ${ }^{\text {KIT D816V }}$ cells}

ROSA KIT WT and ROSA KIT D816V were cultured with 1.25 and $2.5 \mu \mathrm{M}$ SAHA for up to $48 \mathrm{~h}$. A significant decrease in viability was seen already at $24 \mathrm{~h}$ for 1.25 $\mu \mathrm{M}$ SAHA for ROSA ${ }^{\mathrm{KIT} D 816 \mathrm{~V}}$ cells, whereas ROSA ${ }^{\mathrm{KIT} \text { WT }}$ cells needed $2.5 \mu \mathrm{M}$ SAHA for $48 \mathrm{~h}$ in order for SAHA to achieve a significant decrease in cell number (Figure 5A). As for HMC1.2 cells, the decrease in viability was mainly due to apoptotic cell death, and apoptosis occurred earlier and more profoundly in ROSA ${ }^{\text {KIT D816V }}$ compared to ROSA $^{\text {KIT WT }}$ cells (Figure 5A), indicating that SAHA may
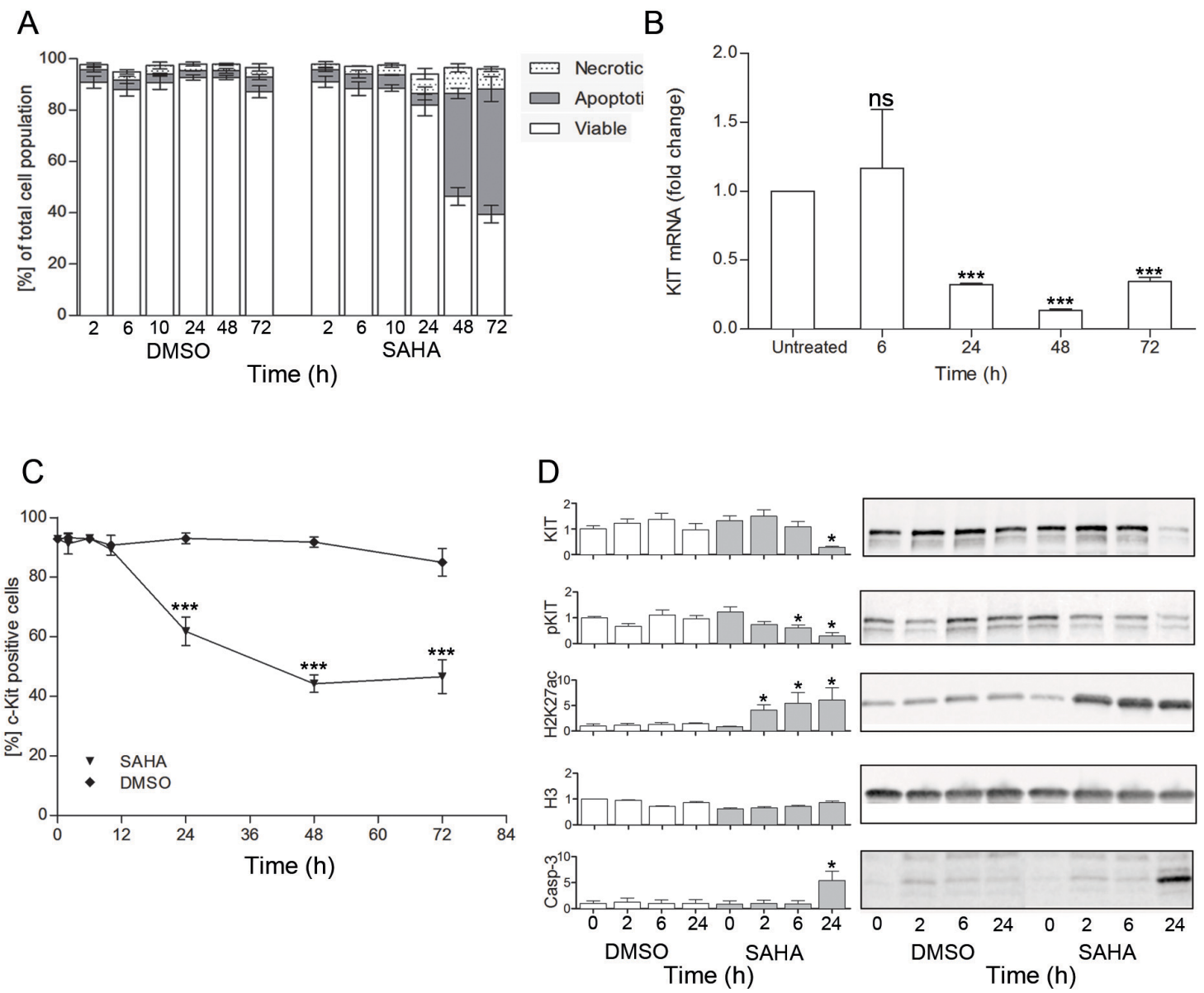

Figure 3: SAHA induces mast cell apoptosis, down-regulation of KIT and increase in H3K27ac. A. Effects of SAHA on cell death revealed a significant increase of apoptotic cell death at $48 \mathrm{~h}(\mathrm{p}<0.01)$, as determined by flow cytometry by Annexin V and propidium iodide staining, $\mathrm{n}=3$; B. A significant decrease of KIT mRNA was seen at $24 \mathrm{~h}(\mathrm{p}<0.05$, duplicates of 4 individual experiments), as was $\mathbf{C}$. a decrease in the percentage of cell surface KIT positive cells $(\mathrm{p}<0.01$ at $24 \mathrm{~h}, 48 \mathrm{~h}$ and $72 \mathrm{~h}$ compared to baseline as well as to DMSO treated cells (triplicate of two separate experiments); D. Western blot analyses showed early responses to SAHA with increased H3K27ac already at $2 \mathrm{~h}$, and decrease in phosphorylated KIT at $6 \mathrm{~h}$, whereas total KIT decreased and active caspase 3 increased significantly at $24 \mathrm{~h}$. Total histone $\mathrm{H} 3$ remained unchanged by SAHA treatment. $*=\mathrm{p}<0.05, * *=\mathrm{p}<0.01$. 
have a selective effect on D816V mutated cells. Similarly, percentage surface KIT positive cells decreased more profoundly in ROSA ${ }^{\text {KIT D816V }}$ cells compared to ROSA ${ }^{\text {KIT }}$ WT (Figure 5B).

When assessing protein levels, we observed a slight, however not significant, increase in active histone mark H3K9ac already at 6h in ROSA ${ }^{\text {KIT D816V }}$ and a significant increase in $\mathrm{H} 3 \mathrm{~K}$ 9ac in ROSA ${ }^{\mathrm{KIT} \text { WT }}$ as well as ROSA ${ }^{\mathrm{KIT}}$ ${ }^{\mathrm{D} 816 \mathrm{~V}}$ at $24 \mathrm{~h}$ also in the lower SAHA concentration (Figure 5C). We also measured total KIT protein however total KIT protein had a strong propensity to increase in the DMSO sample already at $6 \mathrm{~h}$ and profoundly at $24 \mathrm{~h}$, likely due to dense culturing of cells, and there was a significant variation between the 3 biological replicates, which influences the statistical analysis. However, there was a significant decrease in total KIT in ROSA KIT wT (where KIT increased in the DMSO control) but not in ROSA ${ }^{\text {KIT D816V }}$ treated cells (where KIT did not increase in the DMSO control) at $6 \mathrm{~h}$ and $24 \mathrm{~h}$ with the higher SAHA concentration $(\mathrm{p}<0.05)$.

\section{Primary SM patient mast cells are sensitive to SAHA treatment}

To investigate the effect of SAHA on primary MC from three SM patients, one patient with ISM, one patient with ASM, and peripheral blood MC from one patient with mast cell leukemia (MCL), as well as bone marrow MC from two age-matched healthy controls, were treated with SAHA at $5 \mu \mathrm{M}$ for 48 hours. Patient characteristics are described in Table 1 . It is noteworthy that the patient with MCL did not have the classical D816V mutation, but a D820Y KIT mutation. Magnetic bead separated CD117 positive mast cells (confirmed as MCs by tryptase staining) were treated for $48 \mathrm{~h}$ with $5 \mu \mathrm{M}$ SAHA or DMSO control and analyzed by flow cytometry gating on forward scatter and CD117 high positivity. An example of gating strategy is shown in Figure 6A. Staining of bone marrow SM MCs revealed a distinct decrease in the number of tryptase positive cells upon SAHA treatment (Figure 6B).

SAHA induced a dramatic reduction of $\mathrm{MCs}$ expressing high surface KIT, especially in the case of more aggressive disease phenotypes, without affecting surface KIT in the healthy control MCs (Figure 6C). Cell death was close to $100 \%$ in the ASM and MCL patients, less profound in the ISM patient and the healthy control MCs (Figure 6D).

\section{SAHA induces specific epigenetic alterations in the KIT gene of HMC1.2 cells}

To assess whether the SAHA-induced apoptosis involves epigenetic regulation of the KIT gene, we next treated HMC1.2 cells with $5 \mu \mathrm{M}$ SAHA for $24 \mathrm{~h}$, the early $24 \mathrm{~h}$ time point chosen so that major apoptosis would be avoided. At $24 \mathrm{~h}$, samples were subjected to ChIP with H3K18ac active chromatin mark. Following ChIP, qPCR was performed with primers covering the KIT promoter and two upstream sites in the KIT gene (chosen based on modifications according to Ensemble (http://www. ensembl.org) and UCSC (https://genome.ucsc.edu), as
A

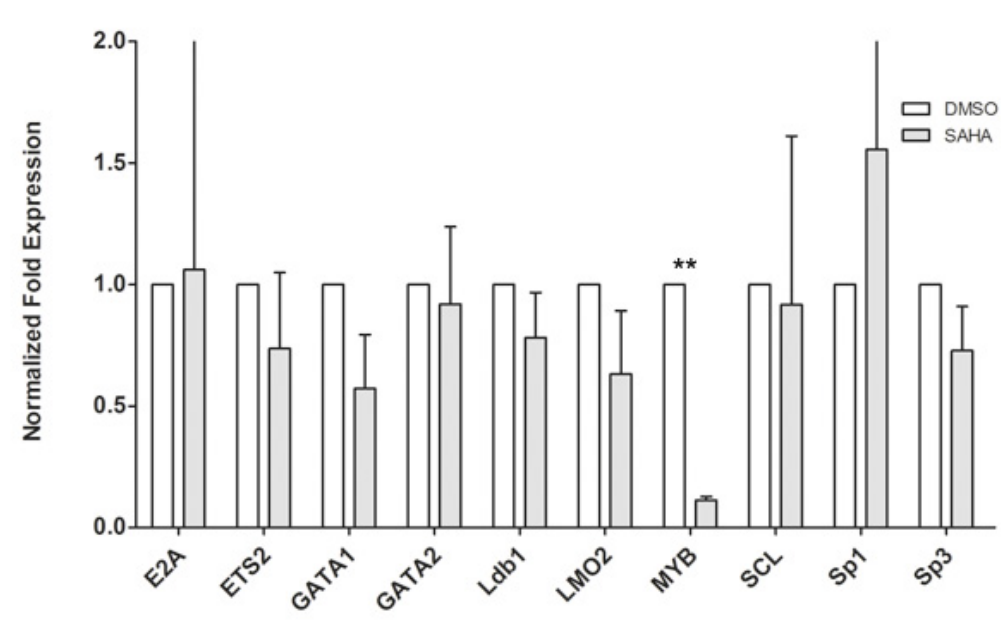

B

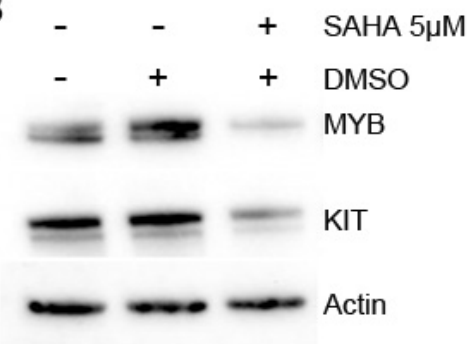

Figure 4: SAHA effects on transcription factors. Ten transcription factors potentially regulating human KIT were assessed for transcript levels after SAHA treatment. SAHA treatment significantly decreased MYB mRNA levels A. and on protein level, where a representative blot is depicted $\mathbf{B}$. White bars are DMSO treated control, grey bars indicate SAHA treatment. $* *=p<0.01$. 
well as two control genes, PDGFR $\alpha$ upstream of KIT, and KDR downstream of KIT (probes schematically drawn in Figure 7A).

In untreated HMC1.2 cells, the level of H3K18ac was high in all regions of the KIT gene, indicating active chromatin, as expected. This was not further increased by SAHA treatment (Figure 7B), likely due to saturation of H3K18ac. In contrast, in adjacent genes PDGFR $\alpha$ and $\mathrm{KDR}, \mathrm{H} 3 \mathrm{~K} 18 \mathrm{ac}$ was low in untreated cells indicating inactive genes, and upon SAHA treatment the genes
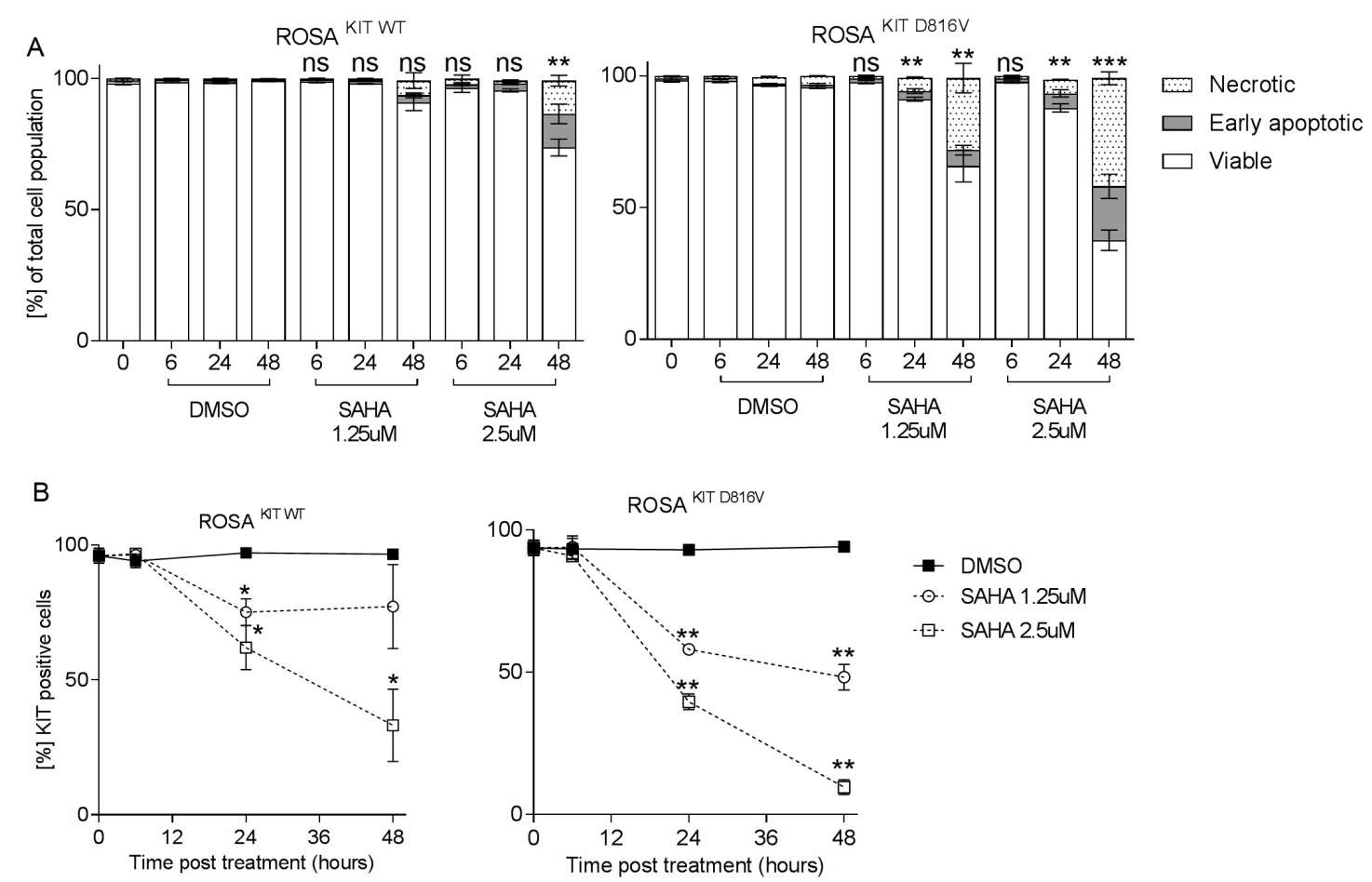

C
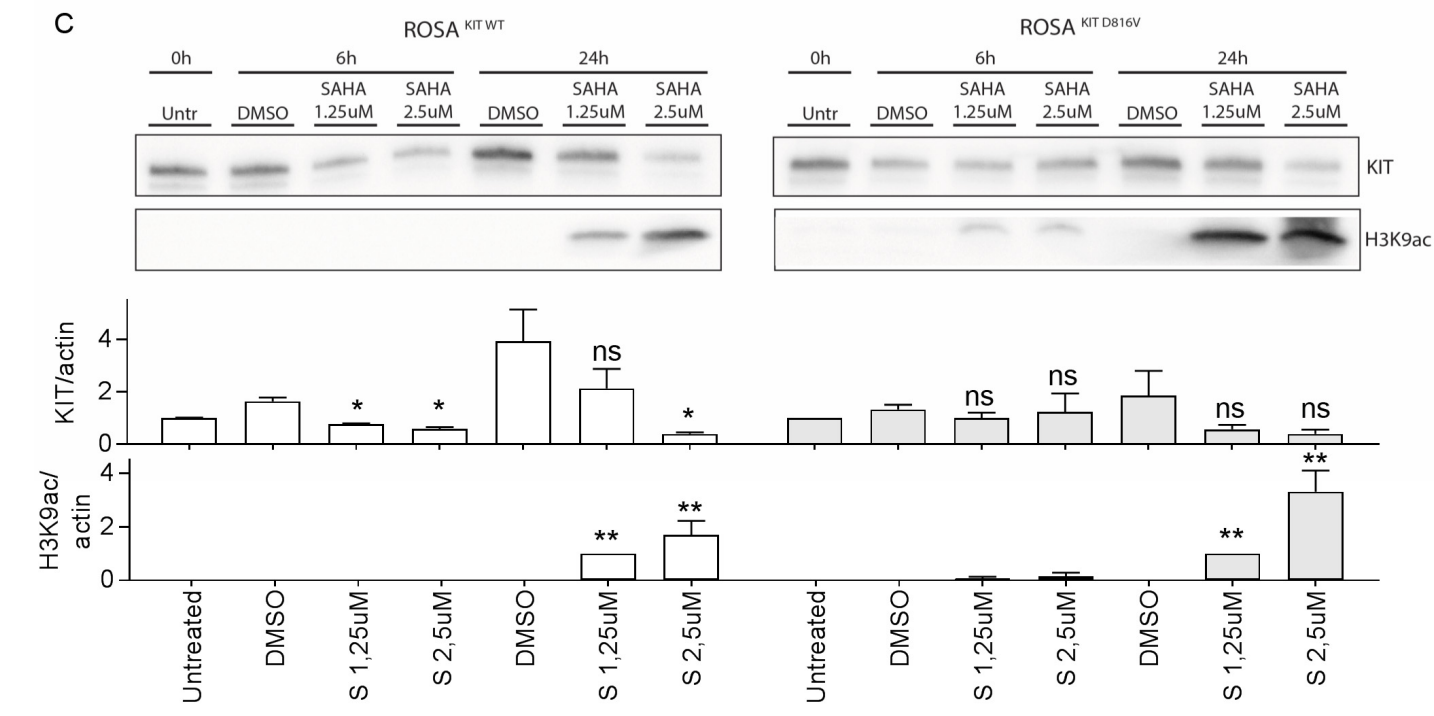

Figure 5: SAHA effects on ROSA ${ }^{\text {KIT }}{ }^{\text {WT }}$ and ROSA ${ }^{\text {KIT D816V }}$ cells. A. SAHA induced a dose- and time-dependent decrease in viability, mainly due to apoptotic cell death, in ROSA cells. The effects were seen earlier and at lower SAHA concentrations in ROSA KIT D816V, where a significant decrease in viability was seen already at $24 \mathrm{~h}$ with $1.25 \mu \mathrm{M}$ SAHA, compared to ROSA ${ }^{\mathrm{KIT}}$ wT. B. There was a significant decrease in percentage KIT positive cells in both cell lines in response to SAHA, and also here ROSA KIT D816V were more profoundly affected by SAHA. C. A significant increase in H3K9ac was seen for both ROSA ${ }^{\text {KIT wT }}$ and ROSA ${ }^{\text {KIT D816V }}$ cells. KIT was significantly decreased in ROSA ${ }^{\text {KIT WT }}$ cells, however note that in the DMSO control, KIT is increasing significantly at 6 and $24 \mathrm{~h}$ compared to baseline, thus the results are difficult to interpret. For ROSA ${ }^{\text {KIT D816V }}$, there is a tendency to decrease in KIT at $24 \mathrm{~h}$ for both SAHA doses. $*=\mathrm{p}<0.05, * *=\mathrm{p}<0.01, * * *=<0.001$. 
Table 1: Characteristics of the SM patients

\begin{tabular}{|c|c|c|c|}
\hline & Patient 1 & Patient 2 & Patient 3 \\
\hline Diagnosis & SM-AHNMD & ISM & MCL \\
\hline Gender & Male & Male & Female \\
\hline Hemoglobin (mg/dL) & 11.6 & 14.5 & 8.3 \\
\hline Leukocytes (x109/L) & 4.4 & 8.4 & 13.5 \\
\hline Platelet count $\left(\times 10^{9} / \mathrm{L}\right)$ & 188 & 229 & 24 \\
\hline Major criteria (mast cell aggregates) & + & + & + \\
\hline Minor criteria: s-tryptase $(\mu \mathrm{g} / \mathrm{L})($ cutoff $<20 \mu \mathrm{g} / \mathrm{L})$ & $180 *$ & 22 & 640 \\
\hline Minor criteria: $\mathrm{BM} \mathrm{MC} \mathrm{CD} 2 / 25$ pos & + & + & Not done \\
\hline Minor criteria: KIT mutation & D816V & D816V & D820Y \\
\hline Minor criteria: Aberrant mast cell phenotype & - & + & - \\
\hline
\end{tabular}

*serum tryptase is not applicable when SM patient has an associated AHNMD. + =present, - absent.

A

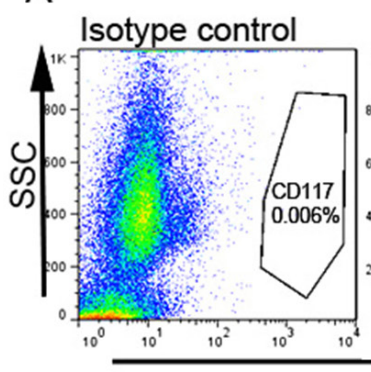

DMSO

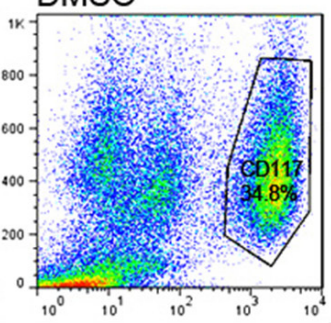

KIT

C

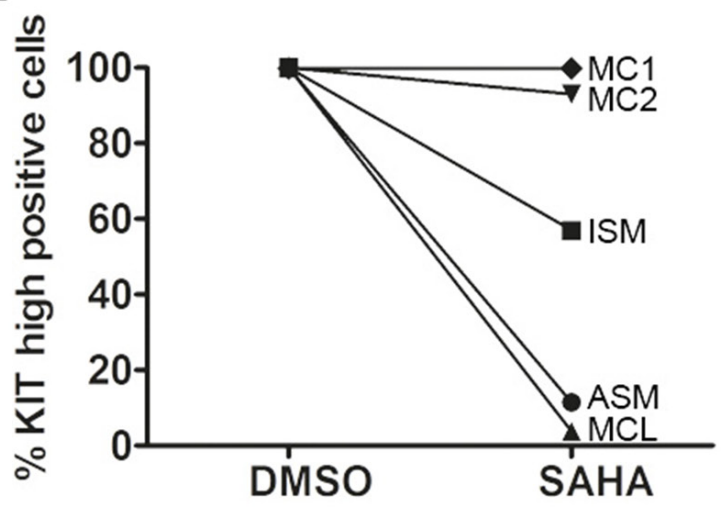

B
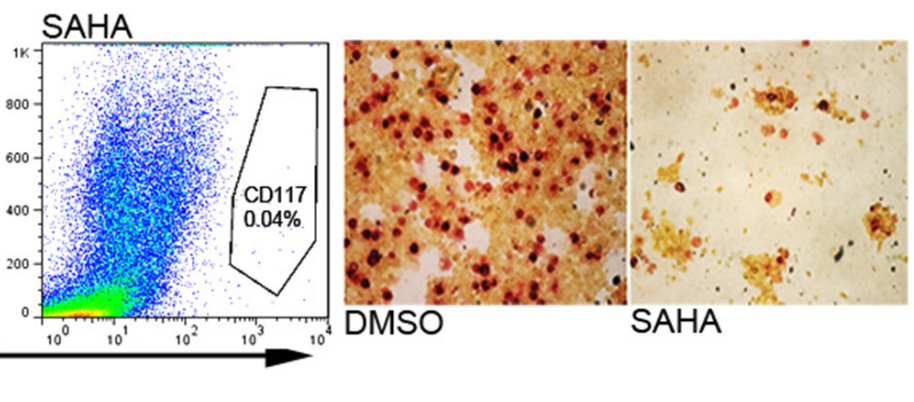

D

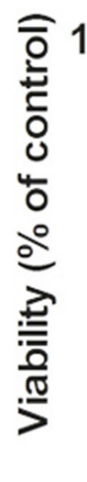

B

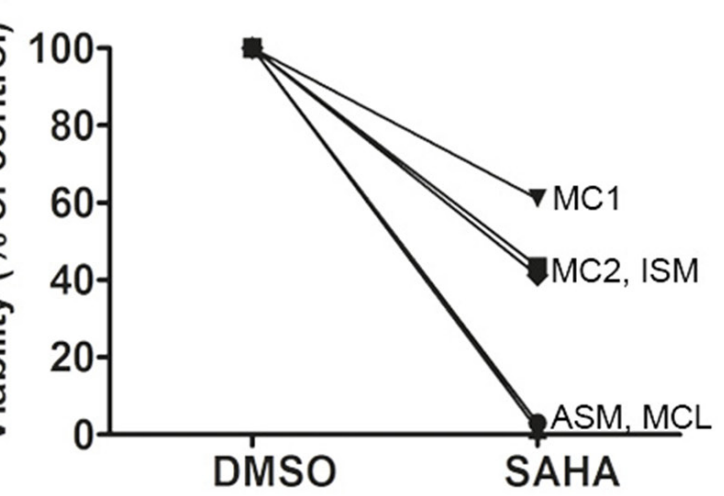

Figure 6: SAHA inhibits KIT-expression and induces cell death in primary SM patient mast cells. A. Flow cytometry gating strategy for side scatter (SSC) and KIT expression (CD117), example of gating for CD117 positive cells. B. Staining of isolated bone marrow MC from a patient with MCL reveals a profound loss of tryptase positive cells upon incubation with 5 $\mathrm{MM}$ SAHA 48h. C. Response of primary SM patient MC and healthy volunteer MC cultured ex vivo with $5 \mu \mathrm{M}$ SAHA for $48 \mathrm{~h}$, show a decrease in surface KIT in all patients, with a more profound decrease the more severe form of SM: ASM and MCL. Non-mutated healthy age matched bone marrow mast cell KIT expression was unaffected by SAHA treatment. D. MC viability shows more cell death induced by SAHA in the more severe forms of SM: ASM and MCL. In the severe SM cases, almost all cells were dead at $48 \mathrm{~h}$ of SAHA treatment. Healthy age-matched bone marrow mast cell viability was less affected by SAHA. 
were acetylated, thus activated, following the predicted pattern of SAHA in increasing histone acetylation. The same pattern in PDGFR $\alpha$ and KDR was seen when the experiment was repeated in healthy unmutated bone marrow MC $(n=2)$, however for these healthy $M C$, we observed as expected that $\mathrm{H} 3 \mathrm{~K} 18 \mathrm{ac}$ was low at baseline in all regions of KIT, indicating inactive KIT, and increased upon SAHA treatment (results not shown).

Unexpectedly, we observed a significant increase in total histone $\mathrm{H} 3$ density upon SAHA treatment, not only in the KIT region but also in PDGFR $\alpha$ and KDR (Figure 7C). This was however not a general genome wide phenomenon, as the total levels of histone $\mathrm{H} 3$ assessed by western blot, remained unchanged upon SAHA treatment (Figure 3D). For accuracy, we re-calculated the levels of $\mathrm{H} 3 \mathrm{~K} 18 \mathrm{ac}$ relative to the $\mathrm{H} 3$ density. This method has been employed by others finding varying total histone $\mathrm{H} 3$ [29]. The levels of $\mathrm{H} 3 \mathrm{~K} 18 \mathrm{ac} / \mathrm{H} 3$ were high at baseline, indicating active chromatin, and decreased significantly in all regions of the KIT gene upon SAHA treatment $(\mathrm{p}<0.05$ for each region in the KIT gene -123 , KIT promoter and -71 , Figure 7D), indicating that SAHA induces a selective silencing of the KIT gene.

To confirm the findings of specific epigenetic effects on KIT compared to surrounding genes, we repeated the treatment of HMC-1.2 with $5 \mu \mathrm{M}$ SAHA for $24 \mathrm{~h}$, thereafter ChIP was performed with antibodies against active $(\mathrm{H} 3 \mathrm{~K} 27 \mathrm{ac})$ and repressive $(\mathrm{H} 3 \mathrm{~K} 27 \mathrm{me} 3$,
H3K9me3) chromatin marks, as well as histone H3 for histone density $(n=2-4)$. For active chromatin mark $\mathrm{H} 3 \mathrm{~K} 27 \mathrm{ac}$, we found a similar pattern to active chromatin $\mathrm{H} 3 \mathrm{~K} 18 \mathrm{ac}$, with high $\mathrm{H} 3 \mathrm{~K} 27 \mathrm{ac}$ levels in the KIT region of untreated cells, which increased significantly in response to SAHA treatment, both in KIT, PDGFR $\alpha$ and KDR (Supplementary Figure 1A). Accordingly, the levels of the repressive marks $\mathrm{H} 3 \mathrm{~K} 9 \mathrm{me} 3$ and $\mathrm{H} 3 \mathrm{~K} 27 \mathrm{me} 3$ were low in the KIT region of untreated HMC1.2 cells, indicating an active gene, and remained unchanged in response to SAHA (Supplementary Figure 1B, 1C). These changes are all in accordance with what is expected regarding the pattern of histone modifications in active genes, and with the general effects of SAHA treatment. In untreated HMC1.2 cells, the repressive chromatin marks were high in PDGFR $\alpha$ and KDR, and the level of active chromatin marks were low, all parameters indicating that PDGFR $\alpha$ and KDR are silent in untreated cells (Supplementary Figure 1). Upon SAHA treatment, the level of active chromatin mark H3K27ac increased in PDGFR $\alpha$ as well as KDR indicating activation, and the repressive marks remained largely unchanged (Supplementary Figure 1). This is in accordance with SAHA exerting its effects as an inhibitor of histone deacetylases, thus increasing histone acetylation. When assessing the levels of active chromatin $\mathrm{H} 3 \mathrm{~K} 27 \mathrm{ac} / \mathrm{H} 3$, there was a significant decrease of active chromatin mark in the KIT promoter region, but not in the control genes, thus showing the same pattern as
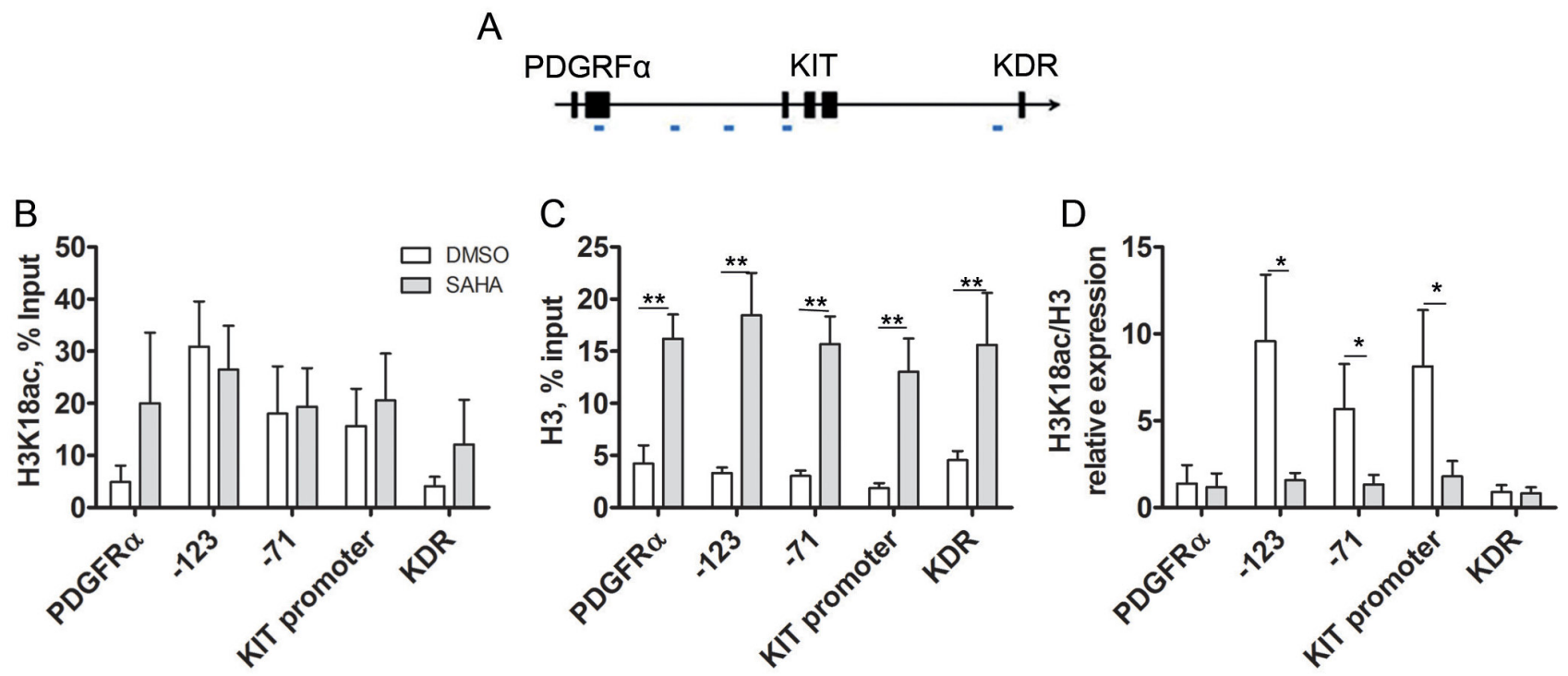

Figure 7: SAHA induces histone acetylation in mast cells. A. Schematic diagram of ChIP qPCR primers over the KIT gene, as well as control genes upstream and downstream of KIT, the PDGFR $\alpha$ and KDR genes, respectively. B. ChIP qPCR of active histone mark H3K18ac $(n=4)$ shows high levels in active KIT, and low levels in control genes. Control gene active H3K18ac increases upon SAHA treatment however the increase was not statistically significant. C. In response to SAHA, histone H3 density increased significantly in the KIT gene as well as in the upstream and downstream genes, PDGFR $\alpha$ and KDR ( $<0.01$ for all regions, $n=5)$. D. ChIP qPCR for $\mathrm{H} 3 \mathrm{~K} 18 \mathrm{ac}$ corrected for $\mathrm{H} 3$ density, $\mathrm{H} 3 \mathrm{~K} 18 \mathrm{ac} / \mathrm{H} 3$ revealed that $\mathrm{H} 3 \mathrm{~K} 18 \mathrm{ac} / \mathrm{H} 3$ was high at baseline indicating active chromatin, and decreased significantly in all regions of the KIT gene upon SAHA treatment ( $p<0.05$ for $-71,-123$ and KIT promoter region), implying specific epigenetic regulation of the KIT gene. The active marks were low in PDGFR $\alpha$ and KDR. White bars are DMSO treated control, grey bars indicate SAHA treatment. 
$\mathrm{H} 3 \mathrm{~K} 18 \mathrm{ac} / \mathrm{H} 3$, supporting the finding of an epigenetic shut down of KIT. In the repressive histone marks relative to $\mathrm{H} 3$ density, H3K9me3/H3 and H3K27me3/H3 were low at baseline and remained low in the KIT region, indicating active chromatin throughout (Supplementary Figure 2B, $2 \mathrm{C})$. In contrast, the repressive chromatin marks in the control genes PDGFR $\alpha$ and KDR were high at baseline and decreased upon SAHA treatment in H3K27me3 (Supplementary Figure 2B, 2C) thus showing a similar pattern as the repressive marks non-adjusted for $\mathrm{H} 3$ density, further implying a specific epigenetic silencing of the KIT gene by SAHA. Taken together, these findings indicate that the constitutively active D816V-mutated KIT characteristic for SM is downregulated by SAHA through epigenetic mechanisms involving reduction in the levels of active chromatin marks $\mathrm{H} 3 \mathrm{~K} 18 \mathrm{ac} / \mathrm{H} 3$ and $\mathrm{H} 3 \mathrm{~K} 27 \mathrm{ac} / \mathrm{H} 3$ specifically in the KIT promoter region. This subsequently leads to MC apoptosis in KIT-mutated cell line HMC1.2 and in SM patient cells, whereas healthy MCs are much less affected.

\section{DISCUSSION}

In the current study, we demonstrate that several HDACi namely SAHA, Panobinostat, Romidepsin and Valproic acid, all induce a dose- and time-dependent growth arrest and cell death of KIT-mutated HMC1.2 cells. The response was most profound for SAHA. Further, SAHA treatment rapidly increased total acetylated histones already after 2 hours of treatment, as well as a decrease in active phosphorylated KIT at 6 hours. This quick increase of acetylated histones is in line with findings in the literature [30]. At $24 \mathrm{~h}$, there was a decrease in KIT mRNA levels, total KIT protein as well as cell surface KIT, followed later by major mast cell apoptosis. The direct causal relationship between KIT mRNA and protein decrease to apoptosis induction remains to be studied, however the events occurred in a distinct time line making a causal relation plausible, and may imply that a decrease in active KIT may have a causative role in the SAHA mediated cell death. Additionally, when comparing ROSA $^{\text {KIT WT }}$ and ROSA ${ }^{\text {KIT D } 816 \mathrm{~V}}$ cells, the SAHA-mediated effects were consistently more profound in ROSA KIT D816V cells.

Furthermore, we show for the first time that primary SM patient KIT positive MCs decrease in cell surface KIT and undergo major cell death in response to SAHA, whereas healthy age-matched bone marrow MC are less affected. Interestingly, cells from the patients with more aggressive SM disease were more sensitive to ex vivo SAHA treatment than cells from ISM and healthy MC and in fact, cells from a patient with highly aggressive MCL were all dead after 48 hours of SAHA exposure. Clinically, these findings are of considerable interest, since there are very limited treatment options for patients with aggressive SM [2, 4-6]. Notably, the ISM and ASM patients both carried the D816V KIT mutation, whereas in the MCL patient we found a more uncommon KIT D820Y mutation. This mutation is also in the intracellular, $2^{\text {nd }}$ catalytic domain close to $\mathrm{D} 816 \mathrm{~V}$, and is reported in around $1 \%$ of GIST [31] and melanoma [32] tumors. As D816V, D820Y is associated with imatinib resistance $[31,32]$. Thus, the SAHA mediated killing seems specific to malignant mast cells when compared to healthy, more profound in KIT mutated compared to WT cells, seemingly regardless of which specific KIT mutation is present.

In addition, we examined the potential effect of SAHA on histone modifications in the KIT gene and control genes PDGFR $\alpha$ upstream and KDR downstream of KIT, by ChIP-qPCR with antibodies to active and repressive chromatin marks. Upon SAHA treatment, histone acetylation marks increased as expected. Surprisingly, we found that upon SAHA treatment of HMC1.2, histone $\mathrm{H} 3$ density increased significantly in the KIT region as well as in adjacent genes PDGFR $\alpha$ and KDR. This was not seen in the chromatin in general, as the total histone $\mathrm{H} 3$ content remained unchanged. To correct for the histone $\mathrm{H} 3$ density, we recalculated the histone $\mathrm{H} 3$ chromatin marks relatively to the total $\mathrm{H} 3$ content in each region of each sample, as has been previously performed in studies with variation in H3 content [29].

In all three regions of the KIT gene, SAHA treatment significantly decreased the active chromatin mark $\mathrm{H} 3 \mathrm{~K} 18 \mathrm{ac} / \mathrm{H} 3$ content. This was also seen for $\mathrm{H} 3 \mathrm{~K} 27 \mathrm{ac}$ in the promoter region of KIT, and is important as $\mathrm{H} 3 \mathrm{~K} 27 \mathrm{ac}$ specifically marks active promoters [33]. This response was unique to the KIT region, and was not seen in the PDGFR $\alpha$ and KDR control genes, where H3K18ac/ $\mathrm{H} 3$ and $\mathrm{H} 3 \mathrm{~K} 27 \mathrm{ac} / \mathrm{H} 3$ levels remained unchanged after SAHA treatment. The decrease in active chromatin mark indicates a specific epigenetic response to SAHA closing the chromatin in the KIT gene, coherent with our current finding of SAHA downregulating KIT mRNA and protein levels. Although this epigenetic regulation and specifically the mechanism behind the increase in $\mathrm{H} 3$ density requires further studies, e.g., by whole genome sequencing at different early time points of treatment and ChIP sequencing or ATAC sequencing with $\mathrm{H} 3$, we hypothesize that the regulation may be exerted by SAHA-induced epigenetic activation of an hitherto unknown upstream negative regulator of the KIT gene.

Altogether, our findings show that SAHA induces apoptotic cell death in mast cell lines as well as in SM patient MCs, whereas healthy bone marrow MCs are less sensitive. SAHA treatment downregulates active phosphorylated KIT, followed by decreased KIT mRNA, protein and surface KIT expression. We demonstrate a decrease in active histone marks in the KIT region in response to SAHA treatment, indicating that SAHA exerts a specific epigenetic downregulation of KIT. Although the epigenetic mechanism of action of SAHA as well as the mutated mast cell selectivity herein described requires 
further investigations, we have demonstrated that mast cells from aggressive SM exhibit high sensitivity to SAHA suggesting that SAHA may be of clinical use for treatment of SM.

\section{MATERIALS AND METHODS}

The study was approved by the local Ethics Committee of Stockholm. Samples from indolent and aggressive SM patients were obtained in connection with routine diagnostic bone marrow sampling, while in the case of the MCL patient, a peripheral blood sample was obtained in conjunction with routine blood sampling, all with oral consent. After oral consent was obtained from healthy (no hematological disorder) individuals scheduled to undergo hip replacement surgery, some of the bone marrow that is removed routinely during surgery was collected for our study. These healthy control samples were confirmed by PCR to be D816V negative.

\section{Culture of mast cell line HMC1.2}

The human mast cell line HMC1.2 [34] was cultured at $37^{\circ} \mathrm{C}$ in a humidified atmosphere with $6 \%$ $\mathrm{CO} 2$, in Iscove's modified Dulbecco's medium (IMDM) supplemented with $10 \%$ fetal bovine serum (FBS, Thermo Fischer Scientific, Waltham, MA, USA), 2 mM L-glutamine (Sigma Aldrich, St Louis, MO, USA), $100 \mu \mathrm{g} / \mathrm{mL}$ streptomycin (Sigma Aldrich), $100 \mathrm{IU} / \mathrm{mL}$ penicillin (Sigma Aldrich), and $1.2 \mathrm{mM}$ 1-thioglycerol (Sigma Aldrich). Experiments were only performed when cells were in logarithmic growth phase and were over $95 \%$ cell surface KIT positive.

\section{Culture of WT and D816V mutated cord blood derived ROSA mast cells}

The human mast cell lines ROSA ${ }^{\text {KIT WT }}$ and ROSA KIT D816V [35] were cultured in IMDM supplemented with $10 \%$ fetal calf serum, $2 \mathrm{mM}$ L-glutamine, $100 \mu \mathrm{g} / \mathrm{mL}$ streptomycin, $100 \mathrm{IU} / \mathrm{mL}$ penicillin. ROSA KIT WT cells where grown with additional $80 \mathrm{ng} / \mathrm{mL}$ murine stem cell factor.

\section{Primary culture of mast cells from SM patients and healthy donors}

Bone marrow samples were first incubated in ammonium chloride buffer for erythrocyte lysis, and thereafter sorted using Miltenyi CD117 microbead kit according to the manufacturer's protocol. For culture experiments, the cells were maintained in StemPro-34 SFM medium supplemented with $100 \mathrm{ng} / \mathrm{ml} \mathrm{rhSCF}$ (SOBI, Stockholm, Sweden) and $10 \mathrm{ng} / \mathrm{ml}$ rhIL-6 (PeproTech EC Ltd, Rocky Hill, USA). Enzymatic tryptase staining was applied to assess the purity of the mast cells, and if less than $50 \%$ were tryptase positive, a second round of magnetic bead CD117 separation was performed. All cells were cultured at $37^{\circ} \mathrm{C}$ in a humidified atmosphere with $6 \%$ $\mathrm{CO} 2$. The viability of patient and healthy mast cells was evaluated with trypan blue exclusion using the Countess ${ }^{\circledR}$ automated cell counter (Invitrogen).

\section{HDACi treatment, cell viability and KIT expression}

Cell line and primary patient or healthy mast cells were treated with SAHA (Cayman Chemical, Ann Arbor, Michigan), Panobinostat (Sigma Aldrich) or Romidepsin (Sigma Aldrich), all dissolved in DMSO, or Valproic acid (Sigma Aldrich) dissolved in distilled water. Control experiments were incubated with DMSO vehicle alone. Viability determination was done with either trypan blue exclusion or using flow cytometry Annexin V-FITC propidium iodide Apoptosis detection Kit according to the manufacturer's protocol (eBioscience). For quantification of KIT expression the HMC-1.2 cells were incubated with $1 \%$ human CD117 (A36E2) (Bioledgend) while for the patient samples we used CD117 (A3C6E2)-PE (Miltenyi Biotec, Bergisch Gladbach, Germany) or 1\% mouse IgG2b isotype control PE (Bioscience, San Jose, CA, USA) for $15 \mathrm{~min}$ at $4^{\circ} \mathrm{C}$. Enriched $\mathrm{CD} 117$ high positive bone marrow cells have previously been described to be highly enriched for mast cells, thus we defined CD117 high positive cells as mast cells [36]. All samples were analyzed on a FACSCalibur flow cytometer (Becton Dickinson), employing the Cellquest software, and the data acquired analyzed with the FlowJo 7.6 program.

For ROSA cells, apoptosis staining was performed with Annexin V and 7-AAD (BD Bioscience) in Annexin V Binding Buffer (BD Bioscience).

\section{Western blot}

Cells were lysed with RIPA buffer on ice, centrifuged and supernatant protein content quantified. Proteins were separated on SDS-polyacrylamide gel electrophoresis (Mini-PROTEAN TGX Precast Gels, Bio-Rad, Hercules, USA); followed by transfer onto a nitrocellulose membrane (Trans-Blot Turbo Mini Nitrocellulose Transfer Packs). The membrane was blocked in Odyssey Blocking buffer (LI-COR, Lincoln, Nebraska, USA) prior to overnight incubation at $4^{\circ} \mathrm{C}$ with one of the following primary antibodies: anti-KIT (D12A3), Caspase 3, phospho-KIT and anti-H3K27Ac (Cell Signaling, Danvers, USA), anti H3 and H3K9ac (Abcam, Cambridge, UK). Subsequently, for HMC1.2 cells, membranes were incubated simultaneously with secondary fluorescent antirabbit and anti-mouse antibodies labeled with spectrally distinct IRDye ${ }^{\circledR}$ fluorescent dyes (wave lengths $680 \mathrm{~nm}$ and $800 \mathrm{~nm}$; LI-COR), and bands were quantified in the Licor development apparatus with Image Studio 4.0 
software (LI-COR). Western blots where analysed and quantified using Image Studio Software version 2.1.10 (LICOR). The protein of interest was normalized to the loading control, $\beta$-actin (DM1A, Sigma) or $\alpha$-tubulin (AC15, Cell signaling). For ROSA cells, membranes were incubated with HRP-conjugated IgG secondary antibody (Cell Signaling, Danvers, USA), proteins visualized with chemiluminescence (GE Healthcare) in a ChemiDoc MP System (Bio-Rad) using Image Lab 4.1. Bands were normalized to $\beta$-actin and vehicle control.

\section{RNA extraction and qPCR}

Total RNA was extracted using Trizol (ThermoFischer Scientific) according to the manufacturer's instructions, with the addition of a second precipitation with absolute ethanol. cDNA was synthesized using Maxima Reverse transcriptase (ThermoFisher Scientific) according to the producers protocol. The subsequent qPCR was performed using $200 \mathrm{nM}$ primer (TaqCopenhagen, Copenhagen, Denmark) and SybGreen (ThermoFisher Scientific) on the StepOnePlus RealTime PCR system (Applied Biosystems). Normalized gene expression was calculated using the CFX manager software (Bio-Rad). The expression was normalized to housekeeping gene GAPDH, and to the DMSO vehicle control.

\section{Transcription factor analysis}

Transcription factors to analyze were chosen by extensive literature search. HMC-1.2 cells were treated with $5 \mu \mathrm{M}$ SAHA or vehicle control for 24 hours, whereafter total RNA was extracted with Trizol and cDNA was synthesized using iScript (Bio-Rad) according to the manufacturer's protocol. Real time PCR was performed using 100 ng cDNA, $200 \mathrm{nM}$ primer (TaqCopenhage) and SybGreen (Bio-Rad) on the CFX96 Touch ${ }^{\mathrm{TM}}$ Real-Time PCR. Gene expression normalized to housekeeping gene was calculated using the CFX manager software (Bio$\mathrm{Rad}$ ), and thereafter normalized to the DMSO vehicle control. Primer list is shown in Supplementary Table 1.

\section{Chromatin immunoprecipitation followed by qPCR (ChIP-qPCR)}

ChIP assay was performed using the iDeal Chipseq kit from Diagenode (Denville, USA) according to the manufacturers procedure. Briefly, after $24 \mathrm{~h}$ incubation with or without SAHA, $10^{6}$ cells were crosslinked, whereafter crosslinking was quenched and nuclei isolated. Chromatin was fragmented using the Bioruptor sonicator (Diagenode) for $25 \mathrm{~min}$ (30 second pulses) to produce fragments of 200-500 nucleotides. Antibodies used for ChIP were: H3K27Ac (Cell
Signaling), H3K27Me3 (Cell Signaling), H3K9Me3 and H3K18Ac (Abcam). Immunoprecipitates were collected using protein A-coated magnetic beads from the iDeal Chip-seq kit (Diagenode). The precipitated DNA was eluted on a rotating wheel for 30 minutes, and crosslinking was reversed by overnight incubation at $65^{\circ} \mathrm{C}$, whereafter DNA was extracted with a PCR purification kit (MiniElute, Qiagen, Hilden, Germany), and qPCR using the primers specific for target gene loci (KIT) was performed. Primers were for KIT promoter forward 5'GCCTTTTCCGTGATCCATTCA3', reverse 5'GGCGACGAGATTAGGCTGTTA3', -71 kb of KIT forward 5' TGCCAGAACATCATTGATATCTCTG'3; reverse 5'CAGGCATGTGGTTGTTAGATATTGT'3; $-123 \mathrm{~kb}$ forward 5' ATG GCT TCT GTC CTT GGA GC'3; reverse 5' GGC CTG ACT GCT TAC TCC TC'3, PDGFR $\alpha$ forward 5' CGCGGTTTTTGAGCCCATTA'3, reverse 5'ATGGAGTAAAGAGCGTGCCC'3, KDR forward 5' GCCTTCAGATGCCACAGACT'3, and reverse 5' TGGCAGCCATATGGAGTTGG'3. For qPCR, $200 \mathrm{nM}$ primer (TaqCopenhage) and SybGreen (Bio-Rad) on the CFX96 Touch ${ }^{\text {TM }}$ Real-Time PCR Detection System (Bio-Rad) was used. Normalized gene expression was calculated using the CFX manager software (Bio-Rad). Enrichment was validated by qPCR with primers specific for the KIT gene including sequences in its promoter, as well as a gene upstream (PDGFR $\alpha$ ) and downstream (KDR) of KIT. The expression was normalized to the percentage of input sample, that is a part of the sample not subjected to ChIP.

\section{Statistical analyses}

Student's paired two-sided t-test was applied to compare treated and untreated samples, with * indicating statistical significance on the level of $p<0.05$, and $* *$ on the level of $p<0.01$. For multiple comparisons between treated and untreated samples over time, ANOVA repeated measures comparing means was applied.

\section{ACKNOWLEDGMENTS}

This work was supported by the Swedish Cancer Society, The Swedish Research Council-Medicine and Health, The Cancer and Allergy Foundation, Ollie and Elof Ericssons Foundation, Hans von Kantzows Foundation, the Swedish Medical Society, the Åke Wiberg Foundation, Marianne and Marcus Wallenberg Foundation, Stockholm Cancer Association, and the Swedish Blood Cancer Association (Blodcancerfonden).

\section{CONFLICTS OF INTEREST}

None of the authors have any conflicts of interest to declare. 


\section{Author contributions}

K.L., H.A.A., J.G, M.K and M.T. performed the laboratory work; H.H. and J.U. provided patient and healthy samples and collected patient information; M.A. provided the ROSA cell line; K.L., J.U. and G.N contributed to the conception and design of the study; K.L., H.A.A. M.T, J.U. and G.N. contributed to the acquisition and analysis of the data; K.L., H.A.A., J.U., and G.N. wrote the first draft of the article; and all authors read and revised the article and gave final approval of the version to be published.

\section{REFERENCES}

1. Arber DA, Orazi A, Hasserjian R, Thiele J, Borowitz MJ, Le Beau MM, Bloomfield CD, Cazzola M, Vardiman JW. The 2016 revision to the World Health Organization classification of myeloid neoplasms and acute leukemia. Blood. 2016; 127:2391-2405.

2. Pardanani A. Systemic mastocytosis in adults: 2015 update on diagnosis, risk stratification, and management. Am J Hematol. 2015; 90:250-262.

3. Theoharides TC, Valent P, Akin C. Mast Cells, Mastocytosis, and Related Disorders. N Engl J Med. 2015; 373:163-172.

4. Arock M, Akin C, Hermine O, Valent P. Current treatment options in patients with mastocytosis: status in 2015 and future perspectives. Eur J Haematol. 2015; 94:474-490.

5. Valent P. Diagnosis and management of mastocytosis: an emerging challenge in applied hematology. Hematology Am Soc Hematol Educ Program. 2015; 2015:98-105.

6. Ustun C, Gotlib J, Popat U, Artz A, Litzow M, Reiter A, Nakamura R, Kluin-Nelemans HC, Verstovsek S, Gajewski J, Perales MA, George T, Shore T, Sperr W, Saber W, Kota $\mathrm{V}$, et al. Consensus Opinion on Allogeneic Hematopoietic Cell Transplantation in Advanced Systemic Mastocytosis. Biol Blood Marrow Transplant. 2016; 22:1348-1356.

7. Metcalfe DD. Mast cells and mastocytosis. Blood. 2008; 112:946-956.

8. Moller C, Alfredsson J, Engstrom M, Wootz H, Xiang Z, Lennartsson J, Jonsson JI, Nilsson G. Stem cell factor promotes mast cell survival via inactivation of FOXO3amediated transcriptional induction and MEK-regulated phosphorylation of the proapoptotic protein Bim. Blood. 2005; 106:1330-1336.

9. Nagata H, Worobec AS, Oh CK, Chowdhury BA, Tannenbaum S, Suzuki Y, Metcalfe DD. Identification of a point mutation in the catalytic domain of the protooncogene c-kit in peripheral blood mononuclear cells of patients who have mastocytosis with an associated hematologic disorder. Proc Natl Acad Sci U S A. 1995; 92:10560-10564.

10. Frost MJ, Ferrao PT, Hughes TP, Ashman LK. Juxtamembrane mutant V560GKit is more sensitive to
Imatinib (STI571) compared with wild-type c-kit whereas the kinase domain mutant D816VKit is resistant. Mol Cancer Ther. 2002; 1:1115-1124.

11. Chandesris MO, Damaj G, Canioni D, Brouzes C, Lhermitte L, Hanssens K, Frenzel L, Cherquaoui Z, Durieu I, Durupt S, Gyan E, Beyne-Rauzy O, Launay D, Faure C, Hamidou M, Besnard S, et al. Midostaurin in Advanced Systemic Mastocytosis. N Engl J Med. 2016; 374:2605-2607.

12. Gotlib J, Kluin-Nelemans HC, George TI, Akin C, Sotlar K, Hermine O, Awan FT, Hexner E, Mauro MJ, Sternberg DW, Villeneuve M, Huntsman Labed A, Stanek EJ, Hartmann K, Horny HP, Valent P, et al. Efficacy and Safety of Midostaurin in Advanced Systemic Mastocytosis. N Engl J Med. 2016; 374:2530-2541.

13. Fong CY, Morison J, Dawson MA. Epigenetics in the hematologic malignancies. Haematologica. 2014; 99:1772-1783.

14. Itzykson R, Fenaux P. Epigenetics of myelodysplastic syndromes. Leukemia. 2014; 28:497-506.

15. Shih AH, Abdel-Wahab O, Patel JP, Levine RL. The role of mutations in epigenetic regulators in myeloid malignancies. Nat Rev Cancer. 2012; 12:599-612.

16. Schwaab J, Schnittger S, Sotlar K, Walz C, Fabarius A, Pfirrmann M, Kohlmann A, Grossmann V, Meggendorfer M, Horny HP, Valent P, Jawhar M, Teichmann M, Metzgeroth G, Erben P, Ernst T, et al. Comprehensive mutational profiling in advanced systemic mastocytosis. Blood. 2013; 122:2460-2466.

17. Soucie E, Brenet F, Dubreuil P. Molecular basis of mast cell disease. Mol Immunol. 2015; 63:55-60.

18. Hanssens K, Brenet F, Agopian J, Georgin-Lavialle S, Damaj G, Cabaret L, Chandesris MO, de Sepulveda P, Hermine O, Dubreuil P, Soucie E. SRSF2-p95 hotspot mutation is highly associated with advanced forms of mastocytosis and mutations in epigenetic regulator genes. Haematologica. 2014; 99:830-835.

19. Jawhar M, Schwaab J, Schnittger S, Meggendorfer M, Pfirrmann M, Sotlar K, Horny HP, Metzgeroth G, Kluger S, Naumann N, Haferlach C, Haferlach T, Valent P, Hofmann WK, Fabarius A, Cross NC, et al. Additional mutations in SRSF2, ASXL1 and/or RUNX1 identify a high-risk group of patients with KIT D816V(+) advanced systemic mastocytosis. Leukemia. 2016; 30:136-143.

20. Jawhar M, Schwaab J, Schnittger S, Sotlar K, Horny HP, Metzgeroth G, Muller N, Schneider S, Naumann N, Walz C, Haferlach T, Valent P, Hofmann WK, Cross NC, Fabarius A, Reiter A. Molecular profiling of myeloid progenitor cells in multi-mutated advanced systemic mastocytosis identifies KIT D816V as a distinct and late event. Leukemia. 2015; 29:1115-1122.

21. Soucie E, Hanssens K, Mercher T, Georgin-Lavialle S, Damaj G, Livideanu C, Chandesris MO, Acin Y, Letard S, de Sepulveda P, Hermine O, Bernard OA, Dubreuil P. In aggressive forms of mastocytosis, TET2 loss cooperates 
with c-KITD816V to transform mast cells. Blood. 2012; 120:4846-4849.

22. West AC, Johnstone RW. New and emerging HDAC inhibitors for cancer treatment. J Clin Invest. 2014; 124:30-39.

23. Bali P, Pranpat M, Bradner J, Balasis M, Fiskus W, Guo F, Rocha K, Kumaraswamy S, Boyapalle S, Atadja P, Seto E, Bhalla K. Inhibition of histone deacetylase 6 acetylates and disrupts the chaperone function of heat shock protein 90: a novel basis for antileukemia activity of histone deacetylase inhibitors. J Biol Chem. 2005; 280:26729-26734.

24. Muhlenberg T, Zhang Y, Wagner AJ, Grabellus F, Bradner J, Taeger G, Lang H, Taguchi T, Schuler M, Fletcher JA, Bauer S. Inhibitors of deacetylases suppress oncogenic KIT signaling, acetylate HSP90, and induce apoptosis in gastrointestinal stromal tumors. Cancer Res. 2009; 69:6941-6950.

25. Glaser KB, Staver MJ, Waring JF, Stender J, Ulrich RG, Davidsen SK. Gene expression profiling of multiple histone deacetylase (HDAC) inhibitors: defining a common gene set produced by HDAC inhibition in T24 and MDA carcinoma cell lines. Mol Cancer Ther. 2003; 2:151-163.

26. Gray SG, Qian CN, Furge K, Guo X, Teh BT. Microarray profiling of the effects of histone deacetylase inhibitors on gene expression in cancer cell lines. Int J Oncol. 2004; 24:773-795.

27. Shao Y, Gao Z, Marks PA, Jiang X. Apoptotic and autophagic cell death induced by histone deacetylase inhibitors. Proc Natl Acad Sci U S A. 2004; 101:18030-18035.

28. Lin TY, Fenger J, Murahari S, Bear MD, Kulp SK, Wang D, Chen CS, Kisseberth WC and London CA. AR-42, a novel HDAC inhibitor, exhibits biologic activity against malignant mast cell lines via down-regulation of constitutively activated Kit. Blood. 2010; 115:4217-4225.

29. Lilja T, Wallenborg K, Bjorkman K, Albage M, Eriksson M, Lagercrantz H, Rohdin M, Hermanson O. Novel alterations in the epigenetic signature of MeCP2-targeted promoters in lymphocytes of Rett syndrome patients. Epigenetics. 2013; 8:246-251.

30. Richon VM, Sandhoff TW, Rifkind RA, Marks PA. Histone deacetylase inhibitor selectively induces p21WAF1 expression and gene-associated histone acetylation. Proc Natl Acad Sci U S A. 2000; 97:10014-10019.

31. Patil DT, Rubin BP. Genetics of Gastrointestinal Stromal Tumors: A Heterogeneous Family of Tumors? Surg Pathol Clin. 2015; 8:515-524.

32. Ashida A, Takata M, Murata H, Kido K, Saida T. Pathological activation of KIT in metastatic tumors of acral and mucosal melanomas. Int J Cancer. 2009; 124:862-868.

33. Heintzman ND, Hon GC, Hawkins RD, Kheradpour P, Stark A, Harp LF, Ye Z, Lee LK, Stuart RK, Ching CW, Ching KA, Antosiewicz-Bourget JE, Liu H, Zhang X, Green RD, Lobanenkov VV, et al. Histone modifications at human enhancers reflect global cell-type-specific gene expression. Nature. 2009; 459:108-112.

34. Sundstrom M, Vliagoftis H, Karlberg P, Butterfield JH, Nilsson K, Metcalfe DD, Nilsson G. Functional and phenotypic studies of two variants of a human mast cell line with a distinct set of mutations in the c-kit proto-oncogene. Immunology. 2003; 108:89-97.

35. Saleh R, Wedeh G, Herrmann H, Bibi S, Cerny-Reiterer S, Sadovnik I, Blatt K, Hadzijusufovic E, Jeanningros S, Blanc C, Legarff-Tavernier M, Chapiro E, Nguyen-Khac F, Subra F, Bonnemye P, Dubreuil P, et al. A new human mast cell line expressing a functional $\mathrm{IgE}$ receptor converts to tumorigenic growth by KIT D816V transfection. Blood. 2014; 124:111-120.

36. Teodosio C, Mayado A, Sanchez-Munoz L, Morgado JM, Jara-Acevedo M, Alvarez-Twose I, Garcia-Montero AC, Matito A, Caldas C, Escribano L, Orfao A. The immunophenotype of mast cells and its utility in the diagnostic work-up of systemic mastocytosis. J Leukoc Biol. 2015; 97:49-59. 